\title{
The Role of Sugar Transporter Genes during Early Infection by Root-Knot Nematodes
}

\author{
Dan Zhao ${ }^{1}$, Yang You ${ }^{1}$, Haiyan Fan ${ }^{1}$, Xiaofeng Zhu ${ }^{1}$, Yuanyuan Wang ${ }^{2}$, Yuxi Duan ${ }^{1}$, \\ Yuanhu Xuan ${ }^{1, *}$ (iD and Lijie Chen ${ }^{1, *}$ \\ 1 College of Plant Protection, Shenyang Agricultural University, Dongling Road 120, Shenyang 110866, China; \\ zhaodan_1201@syau.edu.cn (D.Z.); youyang2015@syau.edu.cn (Y.Y.); fanhaiyan6860@gmail.com (H.F.); \\ syxf2000@syau.edu.cn (X.Z.); duanyx@syau.edu.cn (Y.D.) \\ 2 College of Biotechnology, Shenyang Agricultural University, Dongling Road 120, Shenyang 110866, China; \\ wangyuanyuan2018@gmail.com \\ * Correspondence: xuanyuanhu115@syau.edu.cn (Y.X.); chenlj-0210@syau.edu.cn (L.C.); \\ Tel./Fax: +86-24-8834-2056 (Y.X.); +86-24-8848-7148 (L.C.)
}

Received: 25 December 2017; Accepted: 17 January 2018; Published: 19 January 2018

\begin{abstract}
Although pathogens such as nematodes are known to hijack nutrients from host plants, the mechanisms whereby nematodes obtain sugars from plants remain largely unknown. To determine the effects of nematode infection on host plant sugar allocation, soluble sugar (fructose, glucose, sucrose) content was investigated using high-performance liquid chromatography with refractive index detection and was found to increase significantly in tomato (Solanum lycopersicum, $\mathrm{Sl}$ ) leaves and roots during early infection by root-knot nematodes (RKNs). To further analyze whether sugar transporters played a role in this process, the expression levels of sucrose transporter (SUT/SUC), Sugars Will Eventually be Exported Transporter (SWEET), tonoplast monosaccharide transporter (TMT), and vacuolar glucose transporter (VGT) gene family members were examined by qRT-PCR analysis after RKN infection. The results showed that three SISUTs, 17 SISWEETs, three SITMTs, and SIVGT1 were upregulated in the leaves, whereas three SISUTs, 17 SISWEETs, two SITMTs, and SIVGT1 were induced in the roots. To determine the function of the sugar transporters in the RKN infection process, we examined post-infection responses in the Atsuc2 mutant and pAtSUC2-GUS lines. $\beta$-glucuronidase expression was strongly induced at the infection sites, and RKN development was significantly arrested in the Atsuc2 mutant. Taken together, our analyses provide useful information for understanding the sugar transporter responses during early infection by RKNs in tomato.
\end{abstract}

Keywords: sugar transporter gene; soluble sugar; tomato; Arabidopsis thaliana; root-knot nematode

\section{Introduction}

The root-knot nematodes (RKNs) Meloidogyne incognita are sedentary endoparasitic nematodes that mainly infect the roots of host plants [1]. Second-stage juveniles (J2s), the only infective stage, migrate through intercellular spaces to reach the vascular cylinder [2]. Once they reach a suitable site in the host roots, J2s select several single cells and induce specialized nematode feeding sites. These sites become enlarged and contain multinucleated cells termed giant cells (GCs) [3]. During juvenile development, GCs act as nutrient source tissues, providing the necessary nourishment to the nematodes [4]. In the syncytia which were induced by cyst nematodes, such as Heterodera schachtii, an increase in metabolic activity has been observed also in relation to soluble sugars [5]. However, little is known about the changes in soluble sugars in GCs. In most plant species, soluble sugars mainly include fructose, glucose, and sucrose [6]. Recently, several members of gene families encoding mono- or disaccharide transporters have been characterized, such as sucrose transporter (SUT), Sugars Will Eventually be Exported Transporter (SWEET), tonoplast monosaccharide transporter 
(TMT), and vacuolar glucose transporter (VGT). These sugar transporter genes play key roles in the regulation of plant development and plant responses to pathogens [7-10].

Since the identification of SoSUT1 in spinach (Spinacia oleracea L.), many genes in the SUT family have been isolated from several higher plants [11-16]. Previous studies have shown that SUTs play a key role in plant-pathogen interactions. For example, in maize (Zea mays), the expression of ZmSUT1 is significantly altered in response to infection by Colletotrichum graminicola [17]. Similarly, in cucumber (Cucumis melo), CmSUT1 is activated upon cucumber mosaic virus (CMV) infection in the leaves [18]. Furthermore, AtSUC2 and AtSUC4 are expressed in the syncytia induced by Heterodera schachtii in Arabidopsis thaliana $[19,20]$.

The plant SWEET family is a recently identified family of sugar transporters, which has seven transmembrane helices in eukaryotes [21,22]. According to phylogenetic studies in several plants, SWEET proteins can be classified into four clades [23-28]. Among these, Clades I and II SWEETs typically show a preference for glucose, whereas Clade III SWEETs transport sucrose [21,29]. Clade IV SWEETs are located in the tonoplast, where they are probably involved in the transport of fructose [30,31]. Many studies have shown that SWEETs play a vital role in plant-pathogen interactions [21]. In Arabidopsis, AtSWEET2 encodes a vacuolar glucose transporter, which provides an efficient nutrient-based defense mechanism that contributes to resistance against Pythium irregulare [32]. In grapes (Vitis vinifera), VvSWEET4, which acts as a glucose transporter, is highly induced after infection by the necrotroph Botrytis cinerea [27]. More recently, in sweet potato (Ipomoea batatas), IbSWEET10 was demonstrated to have considerable potential in improving resistance to Fusarium oxysporum [33].

TMTs are localized in the tonoplast and potentially act as $\mathrm{H}^{+}$/sugar antiporters, transporting glucose and fructose into the vacuoles [34]. Under drought, salt, and cold stress, TMT1 and TMT2 were induced in Arabidopsis plants [35]. The VGT family members have the same functions as TMTs, as evidenced by their expression in similar tissues and their preference for transporting glucose [36]. Although the functions of TMTs and VGTs have previously been characterized under abiotic stress [35,37], the roles of the sugar transporter gene families in tomato-RKN interactions remain poorly understood.

In this study, the soluble sugar content and the expression of several sugar transporter gene family members were investigated during early infection by RKNs. We demonstrated that the expression of sugar transport genes and the soluble sugar content were altered by RKN infection. We further demonstrated that, whereas the mutation of AtSUC2 did not inhibit RKN invasion, it did lead to a significant delay in RKN development. Collectively, our results indicate the important role of sugar transport during early infection by RKNs and enhance our understanding of AtSUC2 function in plant-nematode interactions.

\section{Results}

\subsection{Accumulation of Soluble Sugar during Early Infection by Root-Knot Nematodes}

Given that RKNs depend entirely on the host root for nourishment, changes in soluble sugar content may reflect the survival demands of RKNs at different points in time [38]. Generally, the accumulation of soluble sugars in the leaves is dependent on photosynthesis and transport activity from the leaves to the roots [39]. Hence, we examined changes in the soluble sugar (fructose, glucose, and sucrose) contents in both the leaves and roots of 21-day-old tomato plants. In this experiment, the samples were collected at 0,12, 24, 48, and $72 \mathrm{~h}$ postinoculation (hpi) with RKNs (Figure 1A). The results showed that the fructose and glucose content increased marginally from 0 to 48 hpi in the leaves and roots, whereas they were increased significantly at the $72 \mathrm{hpi}$ time point. In addition, compared with $0 \mathrm{~h}$, the sucrose content showed a clear increase at $24 \mathrm{hpi}$ in the roots. Moreover, the maximum sucrose content in both leaves and roots was recorded at $72 \mathrm{hpi}$. Notably, similar trends in fructose, glucose, and sucrose accumulations were observed in the leaves and roots. These results indicated that the soluble sugar content was modulated by early infection with RKNs. 


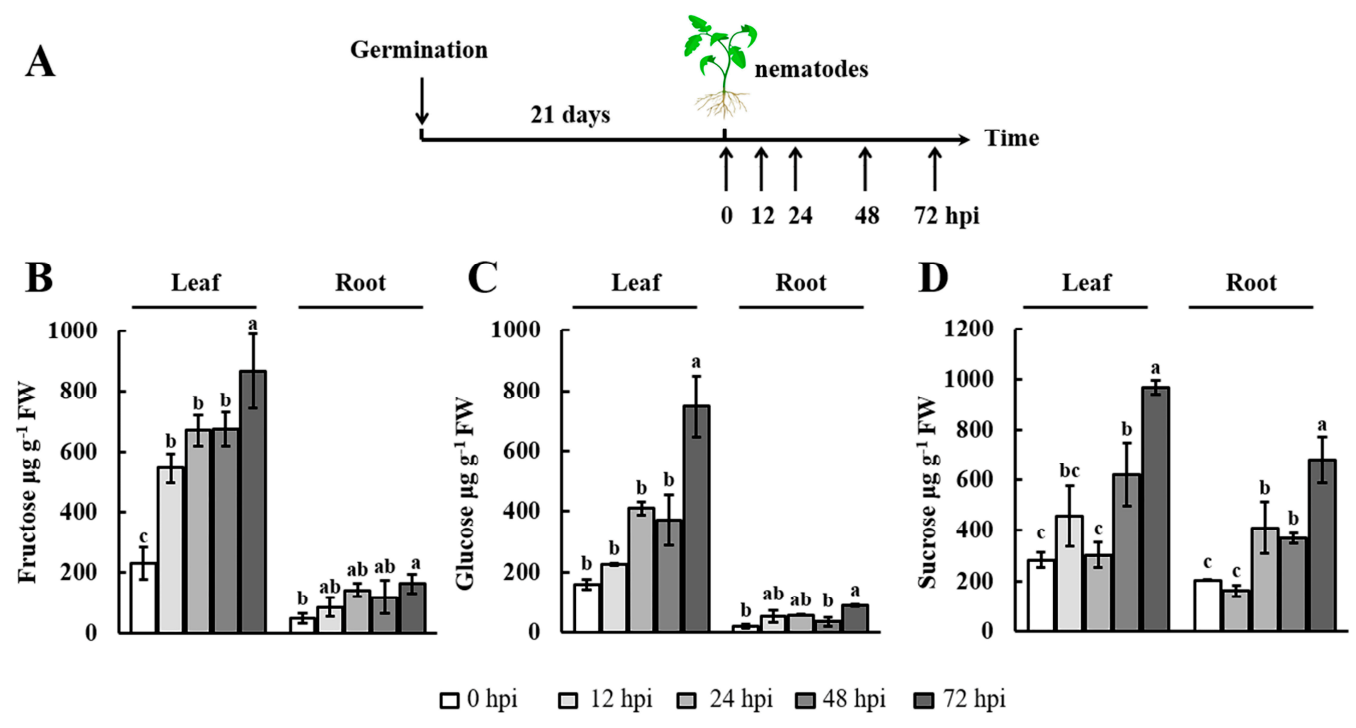

Figure 1. Soluble sugar content in the leaves and roots after nematode infection. (A) Scheme of leaf and root sampling for soluble sugar measurements; (B-D) The soluble sugar content was monitored by high-performance liquid chromatography with refractive index detection (HPLC-RID) in leaves and roots at $0,12,24,48$, and $72 \mathrm{~h}$ postinoculation (hpi) with Meloidogyne incognita. The experiments were repeated three times. Data represent the means \pm SE $(n=3)$. Significant differences $(p<0.05)$ between the groups are indicated by different letters. SE, standard error. FW, fresh weight.

\subsection{Analysis of SlSUT Expression during Early Infection by Root-Knot Nematodes}

SUT family proteins function as key sucrose transporters [24]. We initially studied the phylogenetic relationships between SUT sequences in Arabidopsis thaliana, Oryza sativa, Solanum tuberosum, and Solanum lycopersicum (Sl) (Figure 2A). The SUT sequences in tomato can be classified into three broad classes: SISUT1, SISUT2, and SISUT4. Next, qRT-PCR analysis was used to quantify the expression of SISUTS during early infection by RKNs. The expression of SISUT1 was induced by RKN infection and reached a maximum at $24 \mathrm{hpi}$ in the leaves ( 2.9-fold) and roots ( 5.7 -fold) (Figure 2B). As shown for SISUT2, the maximum expression was recorded at $48 \mathrm{hpi} \mathrm{(} \mathrm{6.3-fold)} \mathrm{and} 72 \mathrm{hpi}$ ( 11.2-fold) in the leaves and roots, respectively (Figure 2C). SISUT4 was strongly expressed at $12 \mathrm{hpi}$ and subsequently maintained a trend of downregulation in both tissues (Figure 2D). These analyses revealed that the expression of SISUTs was highly induced in the leaves and roots at different points of time, suggesting that SISUTs could play an important role during early infection by RKNs.

\subsection{Analysis of SISWEET Expression during Early Infection by Root-Knot Nematodes}

Recently, it has been reported that the SWEET family members play a key role in sugar transport [40]. In tomato, 29 SWEETs have been identified and can be classified into four phylogenetic clades [25], which is similar to the pattern previously reported in Arabidopsis [21] (Figure 3). To investigate the roles of SISWEETS during early infection by RKNs in tomato, the expression of SISWEETs in the leaves and roots was determined by qRT-PCR. In the leaves, among all SISWEETs examined, eight genes (SLSWEET1d, -2a, -2b, -3, -5a, -5b, -7a, -7b) in Clades I and II, eight genes (SISWEET10a, -10b, -10c, -11d, -12a, -12c, -12d, -14) in Clade III, and SISWEET17 in Clade IV were upregulated ( $>2$-fold) at least at one time point, whereas the expression of other genes was downregulated or remained unchanged (Figures 3 and 4). In the roots, eight genes (SINEC1, SISWEET1d, $-1 f,-3,-5 b,-6 a,-7 a,-7 b)$ in Clades I and II, eight genes (SISWEET10a, -11a, -11c, -11d, $-12 a,-12 b,-12 c,-12 d$ ) in Clade III, and SISWEET17 in Clade IV showed enhanced expression (>2-fold), whereas other genes were downregulated or remained unchanged (Figures 3 and 4). Most notably, 10 genes (SISWEET3, $-5 a,-7 a,-7 b,-10 a,-11 d,-12 a,-12 c,-12 d,-17)$ were significantly upregulated in both leaves and roots. 
Overall, these data showed that the expression of SISWEETs was dramatically altered, which suggests an important role of these genes during early infection by RKNs.

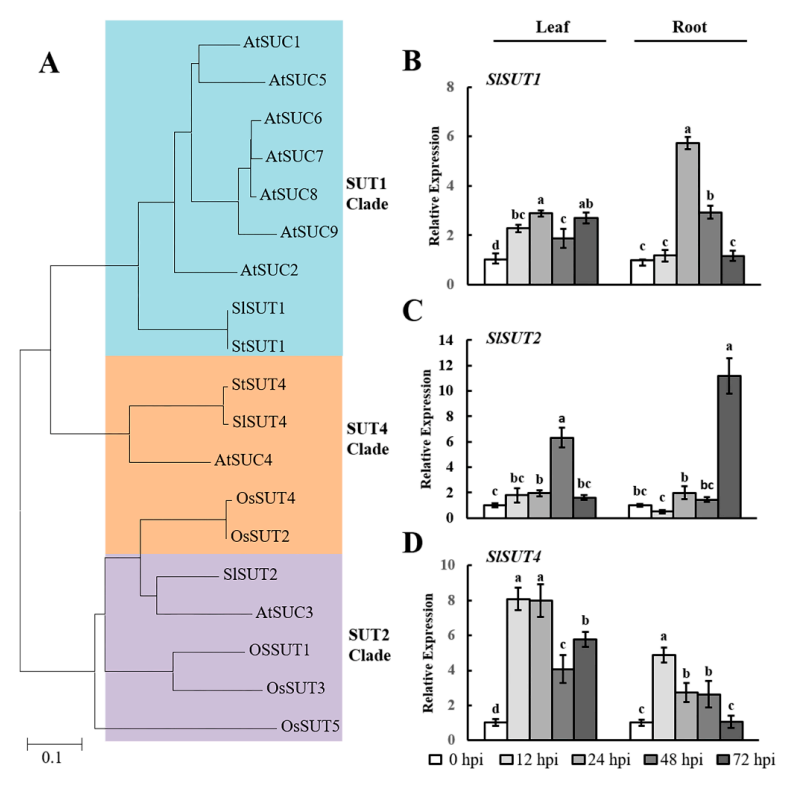

Figure 2. RKN infection-mediated expression of SISUTs in tomato leaves and roots. (A) Phylogenetic analysis of SUT proteins from Arabidopsis thaliana (At), Oryza sativa (Os), Solanum tuberosum (St), and Solanum lycopersicum (Sl). A phylogenetic tree was constructed via the neighbor-joining method with 1000 bootstrap replications. Accession numbers are listed in Supplementary Table S1; (B-D) qRT-PCR was used to quantify SISUT expression at $0,12,24,48$, and $72 \mathrm{~h}$ postinoculation (hpi) with Meloidogyne incognita. Three biological replicates were analyzed and three technical repeats were performed per sample. Error bars indicate the standard deviation (SD) between biological repeats $(n=3)$. Different letters indicate significant differences $(p<0.05)$.

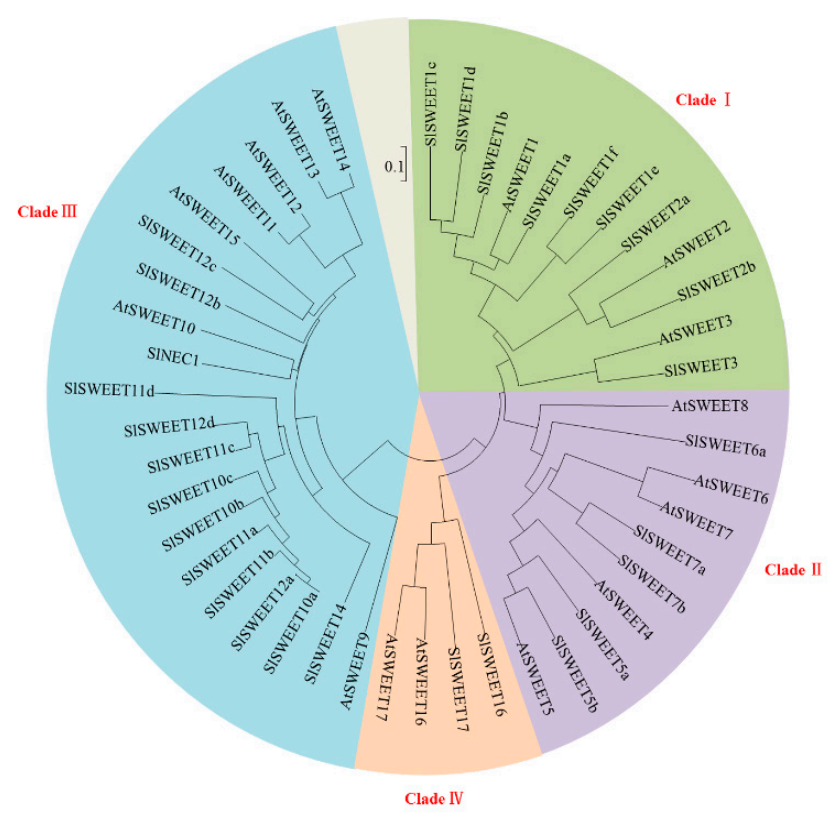

Figure 3. Phylogenetic analysis of SWEET proteins. The conservation of SWEET proteins from Arabidopsis thaliana $(A t)$ and Solanum lycopersicum $(S l)$ was assessed by phylogenetic tree analysis. A phylogenetic tree was constructed via the neighbor-joining method with 1000 bootstrap replications. The accession numbers are listed in Supplementary Table S1. 


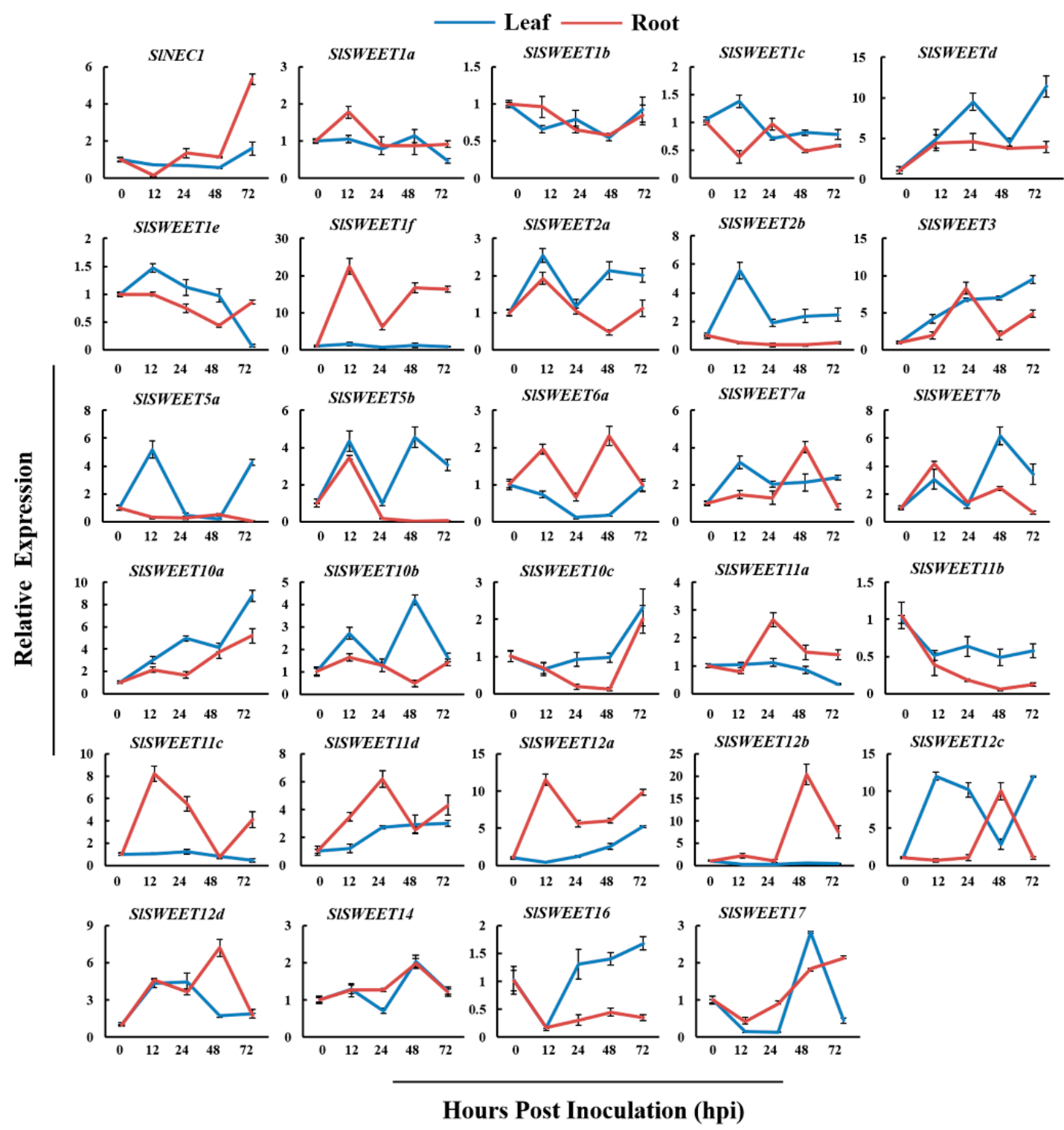

Figure 4. RKNs infection-dependent expression of SISWEETs in tomato leaves and roots. qRT-PCR was used to quantify SISWEET expression at $0,12,24,48$, and $72 \mathrm{~h}$ postinoculation (hpi) with Meloidogyne incognita. Three biological replicates were analyzed and three technical repeats were performed per sample. Error bars indicate the SD between biological repeats $(n=3)$.

\subsection{Analysis of TMT and VGT Expression during Early Infection by Root-Knot Nematodes}

Plants have several small gene families that encode mono- or disaccharide transporters at the plasma membrane or tonoplast [35,41]. Therefore, we selected the TMT and VGT gene families as targets and examined their expression in tomato leaves and roots during early infection by RKNs. TMT and VGT proteins form small subfamilies with three and two members in tomato, respectively (Figure 5A). The results showed that the expression of these genes was enhanced and inhibited at different levels. In the leaves, SITMTs were upregulated at 12, 24, and 48 hpi (Figure 5B-D). In the roots, SITMT1 and SITMT2 were upregulated significantly at 12 and 72 hpi, respectively. Additionally, SITMT2 was upregulated significantly in both the leaves and the roots at $12 \mathrm{hpi}$. The analysis of SIVGTs showed that SIVGT1 was significantly expressed in the leaves and roots (Figure 5E). In contrast, there was no significant difference in the expression of SIVGT2 (Figure 5F). These results indicated that SITMTs and SIVGT1 could play important roles in the response to early RKN infection in tomato. 

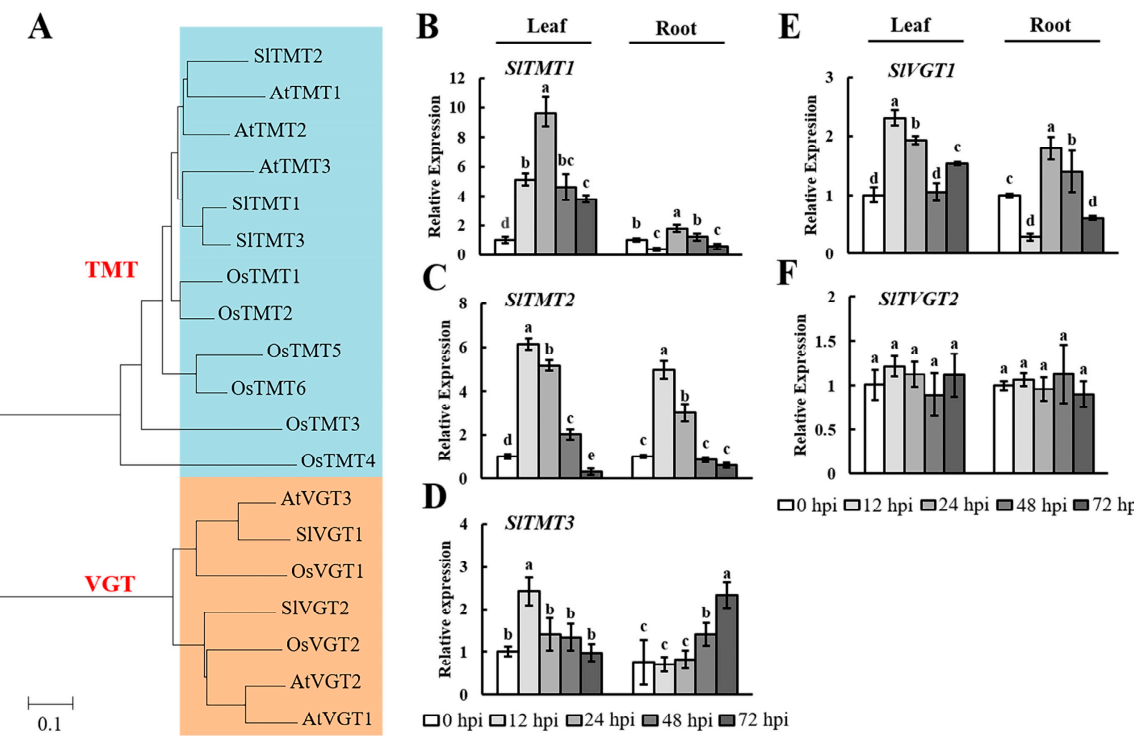

Figure 5. Expression levels of SITMTs and SlVGTs in tomato leaves and roots after RKN infection. (A) Phylogenetic analysis of TMT and VGT proteins from Arabidopsis thaliana (At), Oryza sativa (Os), and Solanum lycopersicum $(S l)$. A phylogenetic tree was constructed using the neighbor-joining method with 1000 bootstrap replications (TMT: blue part; VGT: yellow part). The accession numbers are listed in Supplementary Table S1. qRT-PCR was used to quantify SITMT; (B-D) and SIVGT; (E, F) expression at $0,12,24,48$, and $72 \mathrm{~h}$ postinoculation (hpi) with Meloidogyne incognita. Three biological replicates were analyzed and three technical repeats were performed per sample. Error bars indicate the SD between biological repeats $(n=3)$. Different letters indicate significant differences $(p<0.05)$.

\subsection{The Role of AtSUC2 during Early Infection by Root-Knot Nematodes}

Arabidopsis has been established as an important model system for studying the function of plant genes. The AtSUC2 gene in Arabidopsis has high homology with SISUT1 in tomato [42,43]. Our results revealed that the expression of SISUT1 increased significantly in tomato roots at 24 hpi (Figure 2C). To study the function of SISUT1, we investigated the role of AtSUC2 in RKN attraction, invasion, and development after inoculation. To evaluate the attraction of RKNs near the roots, we counted the number of J2s touching the root tips of the Atsuc2 mutant and wild-type Col-0 plants at 2, 4, 6, 9, 12, and $24 \mathrm{~h}$. The number of J2s touching the roots changed over time, with the highest number being observed at $9 \mathrm{~h}$ (Figure 6A). Furthermore, the number of J2s around the roots was dramatically lower at $24 \mathrm{~h}$, probably because $\mathrm{J} 2 \mathrm{~s}$ had already invaded the roots at this time point. There was no significant difference in the number of J2s attracted to the roots of the Atsuc 2 mutant and wild-type Col-0 plants. Fudali et al. [44] observed that at $24 \mathrm{hpi}$, a large number of RKNs had invaded the roots. Therefore, we selected $24 \mathrm{~h}$ as a suitable time point to perform the invasion assay. Our results showed that there was no significant difference between the Atsuc2 mutant and wild-type Col-0 plants in terms of the number of J2s found in the roots (Figure 6B). To further investigate the role of AtSUC2 during gall formation and RKN development, the number of galls and different stages of RKNs were counted at 15 days postinoculation (dpi). The results showed that there was no difference in the number of galls in the Atsuc2 mutant when compared with the wild type Col-0 (Figure 6C). The analysis of the Atsuc2 mutant showed that the mutation of AtSUC2 led to a lower proportion of fourth-stage juveniles (J4s) than in the wild-type Col-0, and most of the nematodes remained in the third-stage juveniles (J3s) (Figure 6D,E). These results indicated that the mutation of Atsuc2 did not inhibit RKN invasion, but did result in a significant delay in RKN development. 

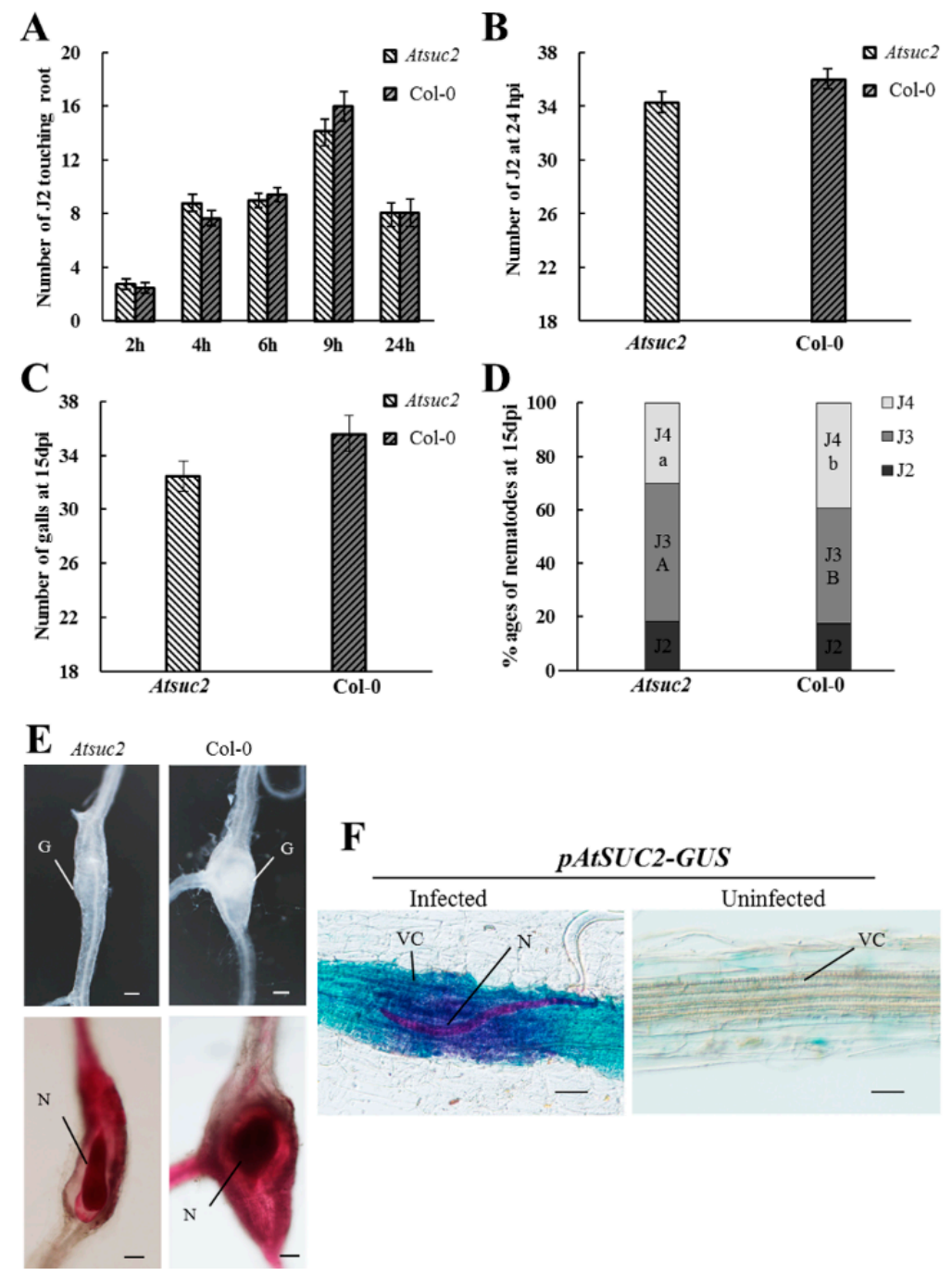

Figure 6. Response of Arabidopsis thaliana suc2 mutants and wild-type Col-0 plants to Meloidogyne incognita infection. (A) Second-stage juveniles (J2s) touching the terminal $7 \mathrm{~mm}$ of the root of the Atsuc2 mutant and wild-type Col-0 plants were counted at 2, 4, 6, 9, and $24 \mathrm{~h}$ in Pluronic F-127 gel ( $n=20)$; (B) Number of nematodes inside the roots of the Atsuc2 mutant and wild-type Col-0 plants at $24 \mathrm{~h}$ post-inoculation (hpi) $(n=30)$; (C) Number of galls at 15 days postinoculation (dpi) $(n=30)$; (D) Percentage of nematodes corresponding to different developmental stages (J3, third-stage juvenile; J4, fourth-stage juvenile) in the Atsuc2 mutant and wild-type Col-0 at $15 \mathrm{dpi}(n=30)$. Different letters indicate statistically significant differences when compared with the wild-type Col-0. (A) or (B) indicate significant differences in the J3 stage; a or b indicate significant differences in the J4 stage; (E) Galls and acid fuchsin-stained nematodes in the Atsuc2 mutant and wild-type Col-0 plants. G, gall; N, nematode. Scale bars $=50 \mu \mathrm{m} ;(\mathbf{F})$ GUS activity was observed in vascular cylinders at 24 hpi. N, nematode; VC, vascular cylinder. Scale bars $=50 \mu \mathrm{m}$. Data represent the means \pm SE. The data of plants in each experiment were analyzed using a $t$-test for independent samples $(p<0.05)$. Similar results were obtained when these experiments were performed in duplicate. SE, standard error.

To analyze the regulation of AtSUC2 in RKN infection, $\beta$-glucuronidase (GUS) assays were performed at $24 \mathrm{hpi}$. An intensive GUS signal was observed in the infected areas of the roots, particularly in the vascular cylinder in Arabidopsis (Figure 6F). The signal remained at a plateau level and was restricted to an area close to the RKN head. The GUS signal was not found in uninfected roots. These results indicated that RKN infection activated the expression of AtSUC2 in Arabidopsis roots. 


\section{Discussion}

Pathogens infect plants in order to hijack host nutrients, particularly sugars [21]. Accordingly, the expression of sugar transporter genes is altered in plants after infection by pathogens. Recently, phylogenetic and functional analyses of sugar transporter gene families (SUT, SWEET, TMT, and VGT) have been conducted for many plant species $[36,45,46]$. To date, however, there have been no reports on the regulation of soluble sugars and the expression of sugar transporter genes in tomato-RKN interactions. In the present study, we observed a dramatic increase in the soluble sugar contents of tomato leaves and roots during early infection by RKNs, with the expression of sugar transporter genes being induced at the same time points. Furthermore, the functional analysis of AtSUC2 demonstrated a strong effect on RKN development. This study revealed the regulation of soluble sugar content and sugar transporter genes in tomato, and enhances our current understanding of AtSUC2 function in Arabidopsis during infection by RKNs.

A previous study revealed that infection by M. incognita alters host plant metabolism, particularly photosynthesis [47]. Therefore, gaining an understanding of the regulation of sugar metabolism and transport will provide a theoretical basis for the prevention of nematode disease. During nematode infection, sugar contents undergo marked changes in Arabidopsis [5], and soluble sugars have been described as playing significant roles during cyst nematode infection [48]. Consistent with the findings of previous research, in our study, we found that the soluble sugar content increased in tomato leaves and roots after RKN infection (Figure 1). At 12 hpi, J2s induced the first GC and started feeding [49]. In this study, we observed a slight increase in the soluble sugar content in the leaves and roots at $12 \mathrm{hpi}$ (Figure 1). During the formation of GCs, the amounts of available soluble sugars must be sufficient to support nematode survival. Our results showed that the soluble sugar content in the leaves and roots dramatically increased to a maximum at $72 \mathrm{hpi} \mathrm{(Figure} \mathrm{1).} \mathrm{These} \mathrm{results} \mathrm{underline} \mathrm{the} \mathrm{importance} \mathrm{of}$ soluble sugars in meeting RKN energy requirements during early infection in tomato.

SUT family members are well established as $\mathrm{H}^{+}$/sucrose symporters [50]. In this study, the sucrose content increased during early infection by RKNs (Figure 1D). This result implied that sucrose could be an important energy source for RKNs. We also observed that the expression of SISUTs was increased during early infection by RKNs (Figure 1C-E). Our findings were consistent with previous studies that reported the importance of AtSUCs in nematode infection in Arabidopsis [4,19,51]. To further explore the function of SUT1, we analyzed the function of AtSUC2 in Arabidopsis, which has high homology to SISUT1 in tomato. The successful infection of plant roots by RKNs necessitates completion of the following phases: effective attraction toward the root tips, establishment of a feeding site, and absorption of nutrients for development [51]. We evaluated these three steps to characterize the role of AtSUC2. On the basis of our results, we concluded that the mutation of AtSUC2 did not inhibit RKN invasion (Figure 6A-C), but did result in a significant delay in RKN development (Figure 6D,E). The mutation of Atsuc2 in Arabidopsis may reduce sucrose translocation in the roots, and, under such circumstances, RKNs would be unable to absorb adequate nutrients to support development. The histochemical analysis using pAtSUC2-GUS transgenic plants revealed that the AtSUC2 gene was induced in the early infection process ( $24 \mathrm{hpi}$ ) at the site of RKN infection (Figure 6F). At 24 hpi, RKNs had invaded throughout the roots and had begun establishing feeding sites [52]. It has been suggested that AtSUC2, as a phloem-specific sucrose transporter, may be crucial for sucrose import into GCs, particularly at $24 \mathrm{hpi}$. A previous study showed that GUS expression was not observed in the feeding cells induced by RKNs in pAtSUC2-GUS plants at $7 \mathrm{dpi}$ [19]. Hence, there may be other sucrose transporter genes that contribute to sucrose availability for RKNs at $7 \mathrm{dpi}$, which is a stage during RKN development when J2 and J3 individuals are dominant. However, it remains to be determined which genes are involved in this process and how they control sucrose accumulation. Accordingly, further studies are needed to elucidate the role of sucrose transporter genes covering the entire life cycle of RKNs.

Plant SWEET proteins are grouped into four clades based on amino acid homologies [25]. Many studies have shown that SWEETs play an important role in plant-pathogen interactions. Clade I 
and II members function as plasma membrane glucose transporters. In rice (Oryza sativa), expression analyses have shown a clear induction of OSSWEET3b by arbuscular mycorrhizal [28]. In Arabidopsis, AtSWEET5 and -7 have been found to be highly induced by Pseudomonas syringae pv. tomato strain DC3000 [21]. Similarly, in the present study, the expression of SISWEET3, $-5 b,-7 a$, and $-7 b$ was highly induced after RKN infection (Figure 4), implying that these genes may play roles during RKN infection or development. Clade III SWEETs have been identified as key factors in sucrose efflux from phloem parenchyma cells [29]. In Arabidopsis, AtSWEET10 expression is induced by Pythium infection in roots [32]. Moreover, AtSWEET12 expression is upregulated by infection with Golovinomyces cichoracearum [21]. In rice, OsSWEET11 is a target of Xanthomonas oryzae pv. oryzae, which probably provides sugars to the site of infection [53]. Consistent with the finding of previous studies, we showed that the expression of SISWEET10a,-11d,-12a,-12c, and -12d followed a similar trend as the changes in sucrose content (Figures 1C and 4). This evidence strongly supports the importance of Clade III SWEETs in the change of sucrose as a source of energy during RKN infection. SWEET17, a member of Clade IV, plays a key role in exporting fructose in Arabidopsis [30,31]. Concomitant with an increase in fructose content, SISWEET17 was highly expressed in both the leaves and the roots (Figures 1B and 4). The results of the gene expression analysis showed that various SISWEETs could be induced by RKNs and played a significant role during early infection by RKNs. In future experiments, it will be of interest to determine the function of these genes in plant-RKN interactions.

In Arabidopsis, TMTs are a type of vacuolar carrier proteins with transport capacity for both glucose and fructose [35]. TMT1 is expressed in Arabidopsis roots infected by M. incognita. [54]. In the present study, SITMTs were strongly expressed during early infection by RKNs, a period that coincides with the phase of glucose and fructose accumulation (Figure 1B,C and Figure 5B-D). Members of the VGT gene family, which is similar to the TMT gene family, play roles in the transport of glucose [37]. In the present study, SIVGT1 was induced during early infection by RKNs, whereas SIVGT2 did not appear to be involved in the change in glucose content in the leaves and roots (Figures $1 \mathrm{C}$ and $5 \mathrm{E}, \mathrm{F}$ ). On the basis of these observations, we speculated that SITMTs and SIVGT1 played an important regulation in the accumulation of glucose and fructose during early infection by RKNs. Further studies are required to elucidate the mechanisms underlying the activities of SITMTs and SIVGT1 in tomato-RKN interactions.

In conclusion, the soluble sugar content was increased in tomato leaves and roots during early infection by RKNs. The sugar content increase in the leaves may be a result of the activation of photosynthesis or the hydrolysis of starch promoted by environmental changes, e.g., RKN infection, whereas an increase in sugar in the roots may be a consequence of sugar translocation from source to sink tissue via transporters. A higher induction of sugar transporter genes might be linked to this process, which will be interesting to examine in further studies. Previous studies have reported that SUT and Clade III SWEET proteins transport sucrose. The excessive accumulation of sucrose may result from the activities of three SISUTS and 11 SISWEETS in Clade III (SISWEET10a, -10b, $-10 c,-11 a,-11 c,-11 d,-12 a,-12 b,-12 c,-12 d,-14)$. In addition, TMT and Clade IV SWEET proteins transport fructose. Three SITMTs and SISWEET17 appear to be involved in changes in fructose content. Whereas VGT and Clade I/II SWEET proteins transport glucose, six SlSWEETs in Clade I (SINEC1, SISWEET1d, -1f, -2a, -2b, -3), five SISWEETS in Clade II (SISWEET5a, -5b, -6a, $-7 a,-7 b$ ), and SIVGT1 may be required for the accumulation of glucose. Furthermore, AtSUC2 was shown to play an important role in the development of RKNs, providing compelling evidence of the importance of sugar transporters in the success of RKN infection of host plants. The results of our study provide baseline information for further studies aimed at understanding the function of sugar transport genes in plant-RKN interactions.

\section{Materials and Methods}

\subsection{Nematode Culture and Inoculum Preparation}

M. incognita was propagated on greenhouse grown tomato, and nematode eggs were collected from 3-month-old heavily galled tomato roots. The roots were washed free of soil with water, cut into 
$1 \mathrm{~cm}$ pieces, and placed in a bottle containing 5.0\% $(v / v)$ sodium hypochlorite ( $\mathrm{NaOCl})$. The bottle was then shaken vigorously for $5 \mathrm{~min}$. This suspension was thoroughly rinsed with tap water through a set of sieves with mesh sizes of 250,150,75, and $25 \mu \mathrm{m}$ to remove the $\mathrm{NaOCl}$. The eggs retained on the $25 \mu \mathrm{m}$-mesh sieve were collected in tap water. The eggs were subsequently collected using the sucrose flotation technique described by Hussey and Baker [55]. RKNs were extracted using the Baermann funnel method [56] and collected every $24 \mathrm{~h}$.

\subsection{Plant Materials and Nematode Inoculations}

Despite its high susceptibility to nematode attack, L-402 is one of the most popular tomato (Solanum lycopersicum) varieties in China. Seeds of L-402 were surface-sterilized in $1 \%$ sodium hypochlorite and sown on substrate soil under greenhouse conditions $\left(22-26{ }^{\circ} \mathrm{C} ; 16 / 8 \mathrm{~h}\right.$, light/dark regime; $70 \%$ relative humidity). Twenty-one-day-old plants were transferred into $12 \mathrm{~cm}$ plastic pots containing $600 \mathrm{~g}$ of soil/sand culture $(1: 1, v / v)$. During the course of the experiment, the plants were watered three times a week and fertilized once a week with half-strength Hoagland nutrient solution. Nematode infection was performed on 21-day-old plants. The plants were inoculated near the root with a mixed population of $M$. incognita at a rate of 1000 per plant. The leaves and roots were harvested at $0,12,24,48$, and $72 \mathrm{~h}$ after inoculation and frozen in liquid nitrogen for analysis.

To assess the role of SUC2 during RKN infection and development, Arabidopsis wild-type Col-0, the Atsuc2 mutant [57], and pAtSUC2-GUS transgenic plants were used. To generate the $p$ AtSUC2-GUS transcriptional construct, $2.5 \mathrm{~kb}$ of the AtSUC2 promoter was amplified by PCR using the primer pair $p$ AtSUC2 GW-F (5'-GGG GAC AAG TTT GTA CAA AAA AGC AGG CTT CGG TAC CGA TTC ATG TCA CTC CTA GCT AG-3') and pAtSUC2 GW-R (5'-GGG GAC CAC TTT GTA CAA GAA AGC TGG GTG ACT AGT TTT GAC AAA CCA AGA AAG TAA G-3'). The PCR product was cloned into pDONR221 using BP clonase (Invitrogen, Carlsbad, CA, USA). After sequencing, the AtSUC2 promoter fragment was inserted into the pMDC163 GW vector via the LR reaction (Invitrogen) [21,29].

For the attraction assay, the seeds of Arabidopsis (wild-type Col-0 and Atsuc2 mutant) were surface-sterilized in $75 \%(v / v)$ ethanol for $15 \mathrm{~min}$, extensively rinsed with sterilized water, and then placed on plates filled with half-strength Murashige and Skoog medium (1/2 MS) containing $0.8 \%$ agar ( $\mathrm{pH}$ 5.7). The seeded plates were incubated for 2 days at $4{ }^{\circ} \mathrm{C}$ and then moved to a culture room under a $16 / 8 \mathrm{~h}$ light/dark regime at $24^{\circ} \mathrm{C}$. After 7 days of growth, Arabidopsis plants were removed from the agar plates and placed in PF-127 medium (23\% $w / v$; Sigma-Aldrich, Saint Louis, MS, USA) containing J2s, as described by Hu et al. [58]. Briefly, the nematode concentration in the PF-127 medium was adjusted to $800 \mathrm{~J} 2 \mathrm{~s} \mathrm{~mL}^{-1}$, and then $0.25 \mathrm{~mL}$ of this solution was added to each well of a 24-well tissue-culture plate, followed by the placement of one Arabidopsis plant into each well. The number of nematodes touching the terminal $7 \mathrm{~mm}$ of the root tip was counted at 2, 4, 6, 9, and $24 \mathrm{~h}$.

For RKN penetration and developmental stage assays, Arabidopsis plants (wild-type Col-0 and Atsuc2 mutant) were grown in sand culture in a growth chamber at $22^{\circ} \mathrm{C}$. Plants were maintained under a diurnal cycle of $16 \mathrm{~h}$ light-8 $\mathrm{h}$ dark throughout the growth period, with light provided by white fluorescent tubes. Two-week-old Arabidopsis plants were inoculated with 200 freshly hatched $\mathrm{J} 2 \mathrm{~s}$, under the same conditions described previously. At $24 \mathrm{~h}$ postinoculation (hpi), the number of nematodes in the roots was estimated using a modified acid fuchsin staining procedure for the RKN penetration assay [59]. At 15 days postinoculation (dpi), the plants were screened, and the gall number was counted for the developmental stage assay. Parasitic J2s subsequently developed into two other juvenile stages, J3 and J4. The number of nematodes in the roots and the different developmental stages were estimated in two independent biological experiments, as previously described.

For GUS assays, Arabidopsis pAtSUC2-GUS plants were grown under the same conditions described for the RKN penetration experiment. Infected and uninfected transgenic root tissues were removed from the soil at $24 \mathrm{hpi}$ and infiltrated overnight with GUS-staining buffer containing X-Gluc (Real-Times Biotechnology, Beijing, China), at $37{ }^{\circ} \mathrm{C}$ in the dark. The following day, the tissues were washed with $70 \%$ ethanol. GUS expression in the roots was monitored microscopically. 
The photographs were taken using an OLYMPUS BX 53 microscope equipped with an Olympus DP 80 digital camera (Tokyo, Japan).

\subsection{Soluble Sugar Analysis}

The soil was washed off the roots of infected and uninfected plants. Ethanol extracts of leaf and root samples were prepared using the method described by Bethke and Busse [60] and analyzed using a high-performance liquid chromatography system (HPLC; Agilent 1100, Palo Alto, CA, USA) equipped with a refractive index detector (RID) Shodex RI-201H (Showa Denko, Tokyo, Japan) on an amine column (Welch ultimate XB-NH${ }_{2}$, Shanghai, China), using a Waters chromatography system. HPLC separations were performed using a $75 \%$ acetonitrile: $25 \%$ alcohol/water mobile phase heated to $30^{\circ} \mathrm{C}$, flowing through the column at a rate of $1.0 \mathrm{~mL} \cdot \mathrm{min}^{-1}$.

\subsection{RNA Isolation and Quantitative Reverse Transcription-PCR (qRT-PCR)}

Total RNA was extracted using the TRIZOL ${ }^{\circledR}$ reagent (CoWin Biosciences, Beijing, China) according to the instructions of the manufacturer. Prior to reverse transcription, the quality of the RNA samples was determined using a NanoDrop 2000 UV-Vis Spectrophotometer (Thermo Scientific, Waltham, MA, USA). cDNA was used for reverse transcription with an oligo (dT) primer, using the HiScript II Q Select RT SuperMix (Vazyme, Nanjing, China). qRT-PCR was then performed using a BIO-RAD CFX96 real-time PCR system (Bio-rad, Berkeley, CA, USA). The reactions were performed in a total volume of $25 \mu \mathrm{L}$ using SYBR $^{\circledR}$ Premix Ex Taq ${ }^{\mathrm{TM}}$ II (Takara, Tokyo, Japan). All reactions were performed under the following conditions: an initial denaturation step $\left(30 \mathrm{~s}\right.$ at $\left.95^{\circ} \mathrm{C}\right)$, followed by 40 cycles of denaturation $\left(5 \mathrm{~s}\right.$ at $\left.95^{\circ} \mathrm{C}\right)$, annealing $\left(30 \mathrm{~s}\right.$ at $\left.60^{\circ} \mathrm{C}\right)$, and extension $\left(1 \mathrm{~min}\right.$ at $\left.72{ }^{\circ} \mathrm{C}\right)$. The cycle threshold $(\mathrm{Ct})$ values were calculated using CFX Manager 3.0, and Microsoft Office Excel was used to calculate transcript abundance from $C t$ values normalized to the actin gene signal. The gene relative expression levels were calculated according to the $2^{-\Delta \Delta C t}$ method [61]. The primers used for qTR-PCR assays are listed in Supplementary Table S2.

\subsection{Statistical Analysis}

All statistical analyses were performed using the analysis of variance (ANOVA) with the SPSS statistical software package (Version 17.0; SPSS, Inc., Chicago, IL, USA) and Microsoft Office Excel 2010. The differences between the two groups were analyzed using the Student's $t$-test, whereas the differences among multiple treatments were analyzed using Duncan's multiple range test. All differences were tested for significance at the $p<0.05$ level.

Supplementary Materials: Supplementary materials can be found at www.mdpi.com/1422-0067/19/1/302/s1.

Acknowledgments: This research was funded by the National Natural Science Foundation of China (31471748; 31330063) and the Tianzhu Mountain Scholars Program of Shenyang Agricultural University. We gratefully acknowledge the Frommer Lab (Carnegie Institution for Science) for providing the seeds of $p$ AtSUC2-GUS; the Atsuc2 mutant seeds were kindly donated by Che Wang of Shenyang Agricultural University.

Author Contributions: Dan Zhao, Yuanhu Xuan, and Lijie Chen conceived and designed the experiments; Dan Zhao and Yang You performed the experiments; Xiaofeng Zhu contributed to data analysis; Yuanyuan Wang and Yuxi Duan provided guidance throughout the entire study; Dan Zhao, Haiyan Fan, Yuanhu Xuan, and Lijie Chen wrote and revised the manuscript; all authors approved the final manuscript.

Conflicts of Interest: The authors have declared that no competing interests exist.

\section{Abbreviations}

$\begin{array}{ll}\text { SUT/SUC } & \text { Sucrose transporter } \\ \text { SWEET } & \text { Sugars will eventually be exported transporter } \\ \text { TMT } & \text { Tonoplast monosaccharide transporter } \\ \text { VGT } & \text { Vacuolar glucose transporter } \\ \text { RKN } & \text { Root-knot nematode }\end{array}$




$\begin{array}{ll}\text { GC } & \text { Giant cell } \\ \text { J2 } & \text { Second-stage juvenile } \\ \text { J3 } & \text { Third-stage juvenile } \\ \text { J4 } & \text { Fourth-stage juvenile } \\ \text { hpi } & \text { Hours post-inoculation } \\ \text { dpi } & \text { Days post-inoculation } \\ \text { NaOCl } & \text { Sodium hypochlorite } \\ \text { MS } & \text { Murashige and Skoog medium } \\ \text { GUS } & \text { B-Glucuronidase } \\ \text { HPLC } & \text { High-performance liquid chromatography } \\ \text { RID } & \text { Refractive index detector } \\ \text { qRT-PCR } & \text { Quantitative reverse transcription-PCR }\end{array}$

\section{References}

1. Favery, B.; Quentin, M.; Jaubert-Possamai, S.; Abad, P. Gall-forming root-knot nematodes hijack key plant cellular functions to induce multinucleate and hypertrophied feeding cells. J. Insect Physiol. 2016, 84, 60-69. [CrossRef] [PubMed]

2. Rodiuc, N.; Vieira, P.; Banora, M.Y.; de Almeida Engler, J. On the track of transfer cell formation by specialized plant-parasitic nematodes. Front. Plant Sci. 2014, 5, 160. [CrossRef] [PubMed]

3. Sijmons, P.C.; Grundler, F.M.; Mende, N.; Burrows, P.R.; Wyss, U. Arabidopsis thaliana as a new model host for plant-parasitic nematodes. Plant J. 1991, 1, 245-254. [CrossRef]

4. Hofmann, J.; Grundler, F.M. How do nematodes get their sweets? Solute supply to sedentary plant-parasitic nematodes. Nematology 2007, 9, 451-458. [CrossRef]

5. Hofmann, J.; Hess, P.H.; Szakasits, D.; Blochl, A.; Wieczorek, K.; Daxbock-Horvath, S.; Bohlmann, H.; van Bel, A.J.; Grundler, F.M. Diversity and activity of sugar transporters in nematode-induced root syncytia. J. Exp. Bot. 2009, 60, 3085-3095. [CrossRef] [PubMed]

6. Jiang, H.Y.; Li, W.; He, B.J.; Gao, Y.H.; Lu, J.X. Sucrose metabolism in grape (Vitis vinifera L.) branches under low temperature during overwintering covered with soil. Plant Growth Regul. 2014, 72, 229-238. [CrossRef]

7. Aoki, N.; Whitfeld, P.; Hoeren, F.; Scofield, G.; Newell, K.; Patrick, J.; Offler, C.; Clarke, B.; Rahman, S.; Furbank, R.T. Three sucrose transporter genes are expressed in the developing grain of hexaploid wheat. Plant Mol. Biol. 2002, 50, 453-462. [CrossRef] [PubMed]

8. Fernandez, O.; Bethencourt, L.; Quero, A.; Sangwan, R.S.; Clement, C. Trehalose and plant stress responses: Friend or foe? Trends Plant Sci. 2010, 15, 409-417. [CrossRef] [PubMed]

9. Lalonde, S.; Wipf, D.; Frommer, W.B. Transport mechanisms for organic forms of carbon and nitrogen between source and sink. Annu. Rev. Plant Biol. 2004, 55, 341-372. [CrossRef] [PubMed]

10. Lemoine, R.; La Camera, S.; Atanassova, R.; Dedaldechamp, F.; Allario, T.; Pourtau, N.; Bonnemain, J.L.; Laloi, M.; Coutos-Thevenot, P.; Maurousset, L.; et al. Source-to-sink transport of sugar and regulation by environmental factors. Front. Plant Sci. 2013, 4, 272. [CrossRef] [PubMed]

11. Berthier, A.; Meuriot, F.; Dedaldechamp, F.; Lemoine, R.; Prud'homme, M.P.; Noiraud-Romy, N. Identification of a new sucrose transporter in rye-grass (LpSUT2): Effect of defoliation and putative fructose sensing. Plant Physiol. Biochem. 2014, 84, 32-44. [CrossRef] [PubMed]

12. Boorer, K.J.; Loo, D.D.; Frommer, W.B.; Wright, E.M. Transport mechanism of the cloned potato $\mathrm{H}^{+} / \mathrm{sucrose}^{-}$ cotransporter StSUT1. J. Biol. Chem. 1996, 271, 25139-25144. [CrossRef] [PubMed]

13. Frost, C.J.; Nyamdari, B.; Tsai, C.J.; Harding, S.A. The tonoplast-localized sucrose transporter in Populus (PtaSUT4) regulates whole-plant water relations, responses to water stress, and photosynthesis. PLoS ONE 2012, 7, e44467. [CrossRef] [PubMed]

14. Noiraud, N.; Delrot, S.; Lemoine, R. The sucrose transporter of celery. Identification and expression during salt stress. Plant Physiol. 2000, 122, 1447-1455. [CrossRef] [PubMed]

15. Riesmeier, J.W.; Willmitzer, L.; Frommer, W.B. Isolation and characterization of a sucrose carrier cDNA from spinach by functional expression in yeast. EMBO J. 1992, 11, 4705-4713. [PubMed] 
16. Sauer, N.; Stolz, J. SUC1 and SUC2: Two sucrose transporters from Arabidopsis thaliana; expression and characterization in baker's yeast and identification of the histidine-tagged protein. Plant J. 1994, 6, 67-77. [CrossRef] [PubMed]

17. Vargas, W.A.; Martin, J.M.; Rech, G.E.; Rivera, L.P.; Benito, E.P.; Diaz-Minguez, J.M.; Thon, M.R.; Sukno, S.A. Plant defense mechanisms are activated during biotrophic and necrotrophic development of Colletotricum graminicola in maize. Plant Physiol. 2012, 158, 1342-1358. [CrossRef] [PubMed]

18. Gil, L.; Yaron, I.; Shalitin, D.; Sauer, N.; Turgeon, R.; Wolf, S. Sucrose transporter plays a role in phloem loading in CMV-infected melon plants that are defined as symplastic loaders. Plant J. 2011, 66, 366-374. [CrossRef] [PubMed]

19. Juergensen, K.; Scholz-Starke, J.; Sauer, N.; Hess, P.; van Bel, A.J.; Grundler, F.M. The companion cell-specific Arabidopsis disaccharide carrier AtSUC2 is expressed in nematode-induced syncytia. Plant Physiol. 2003, 131, 61-69. [CrossRef] [PubMed]

20. Morkunas, I.; Ratajczak, L. The role of sugar signaling in plant defense responses against fungal pathogens. Acta Physiol. Plant. 2014, 36, 1607-1619. [CrossRef]

21. Chen, L.Q.; Hou, B.H.; Lalonde, S.; Takanaga, H.; Hartung, M.L.; Qu, X.Q.; Guo, W.J.; Kim, J.G.; Underwood, W.; Chaudhuri, B.; et al. Sugar transporters for intercellular exchange and nutrition of pathogens. Nature 2010, 468, 527-532. [CrossRef] [PubMed]

22. Xuan, Y.H.; Hu, Y.B.; Chen, L.Q.; Sosso, D.; Ducat, D.C.; Hou, B.H.; Frommer, W.B. Functional role of oligomerization for bacterial and plant SWEET sugar transporter family. Proc. Natl. Acad. Sci. USA 2013, 110, E3685-E3694. [CrossRef] [PubMed]

23. Manck-Gotzenberger, J.; Requena, N. Arbuscular mycorrhiza symbiosis induces a major transcriptional reprogramming of the potato SWEET sugar transporter family. Front. Plant Sci. 2016, 7, 487. [CrossRef] [PubMed]

24. Jameson, P.E.; Dhandapani, P.; Novak, O.; Song, J. Cytokinins and expression of SWEET, SUT, CWINV and $A A P$ genes increase as pea seeds germinate. Int. J. Mol. Sci. 2016, 17, 2013. [CrossRef] [PubMed]

25. Feng, C.Y.; Han, J.X.; Han, X.X.; Jiang, J. Genome-wide identification, phylogeny, and expression analysis of the SWEET gene family in tomato. Gene 2015, 573, 261-272. [CrossRef] [PubMed]

26. Patil, G.; Valliyodan, B.; Deshmukh, R.; Prince, S.; Nicander, B.; Zhao, M.Z.; Sonah, H.; Song, L.; Lin, L.; Chaudhary, J.; et al. Soybean (Glycine max) SWEET gene family: Insights through comparative genomics, transcriptome profiling and whole genome re-sequence analysis. BMC Genom. 2015, 16, 520. [CrossRef] [PubMed]

27. Chong, J.; Piron, M.C.; Meyer, S.; Merdinoglu, D.; Bertsch, C.; Mestre, P. The SWEET family of sugar transporters in grapevine: VvSWEET4 is involved in the interaction with Botrytis cinerea. J. Exp. Bot. 2014, 65, 6589-6601. [CrossRef] [PubMed]

28. Yuan, M.; Wang, S.P. Rice MtN3/Saliva/SWEET family genes and their homologs in cellular organisms. Mol. Plant 2013, 6, 665-674. [CrossRef] [PubMed]

29. Chen, L.Q.; Qu, X.Q.; Hou, B.H.; Sosso, D.; Osorio, S.; Fernie, A.R.; Frommer, W.B. Sucrose efflux mediated by SWEET proteins as a key step for phloem transport. Science 2012, 335, 207-211. [CrossRef] [PubMed]

30. Guo, W.J.; Nagy, R.; Chen, H.Y.; Pfrunder, S.; Yu, Y.C.; Santelia, D.; Frommer, W.B.; Martinoia, E. SWEET17, a facilitative transporter, mediates fructose transport across the tonoplast of Arabidopsis roots and leaves. Plant Physiol. 2014, 164, 777-789. [CrossRef] [PubMed]

31. Chardon, F.; Bedu, M.; Calenge, F.; Klemens, P.A.W.; Spinner, L.; Clement, G.; Chietera, G.; Leran, S.; Ferrand, M.; Lacombe, B.; et al. Leaf fructose content is controlled by the vacuolar transporter SWEET17 in Arabidopsis. Curr. Biol. 2013, 23, 697-702. [CrossRef] [PubMed]

32. Chen, H.Y.; Huh, J.H.; Yu, Y.C.; Ho, L.H.; Chen, L.Q.; Tholl, D.; Frommer, W.B.; Guo, W.J. The Arabidopsis vacuolar sugar transporter SWEET2 limits carbon sequestration from roots and restricts Pythium infection. Plant J. 2015, 83, 1046-1058. [CrossRef] [PubMed]

33. Li, Y.; Wang, Y.; Zhang, H.; Zhang, Q.; Zhai, H.; Liu, Q.; He, S. The plasma membrane-localized sucrose transporter IbSWEET10 Contributes to the resistance of sweet potato to Fusarium oxysporum. Front. Plant Sci. 2017, 8, 197. [CrossRef] [PubMed]

34. Schulz, A.; Beyhl, D.; Marten, I.; Wormit, A.; Neuhaus, E.; Poschet, G.; Buttner, M.; Schneider, S.; Sauer, N.; Hedrich, R. Proton-driven sucrose symport and antiport are provided by the vacuolar transporters SUC4 and TMT1/2. Plant J. 2011, 68, 129-136. [CrossRef] [PubMed] 
35. Wormit, A.; Trentmann, O.; Feifer, I.; Lohr, C.; Tjaden, J.; Meyer, S.; Schmidt, U.; Martinoia, E.; Neuhaus, H.E. Molecular identification and physiological characterization of a novel monosaccharide transporter from Arabidopsis involved in vacuolar sugar transport. Plant Cell 2006, 18, 3476-3490. [CrossRef] [PubMed]

36. Reuscher, S.; Akiyama, M.; Yasuda, T.; Makino, H.; Aoki, K.; Shibata, D.; Shiratake, K. The sugar transporter inventory of tomato: Genome-wide identification and expression analysis. Plant Cell Physiol. 2014, 55, 1123-1141. [CrossRef] [PubMed]

37. Xu, H.F.; Liu, J.X.; Wang, Y.C.; Zuo, W.F.; Qu, C.Z.; Wang, D.Y.; Zhang, J.; Jiang, S.H.; Wang, N.; Chen, X.S. Isolation and expression analysis of a vacuolar glucose transporter gene MdVGT1 in Apple. Sci. Agric. Sin. 2016, 49, 4584-4592. [CrossRef]

38. Caillaud, M.C.; Dubreuil, G.; Quentin, M.; Perfus-Barbeoch, L.; Lecomte, P.; de Almeida Engler, J.; Abad, P.; Rosso, M.N.; Favery, B. Root-knot nematodes manipulate plant cell functions during a compatible interaction. J. Plant Physiol. 2008, 165, 104-113. [CrossRef] [PubMed]

39. Bürkle, L.; Hibberd, J.M.; Quick, W.P.; Kühn, C.; Hirner, B.; Frommer, W.B. The $\mathrm{H}^{+}$-sucrose cotransporter NtSUT1 is essential for sugar export from tobacco leaves. Plant Physiol. 1998, 118, 59-68. [CrossRef] [PubMed]

40. Chen, L.Q. SWEET sugar transporters for phloem transport and pathogen nutrition. New Phytol. 2014, 201, 1150-1155. [CrossRef] [PubMed]

41. Aluri, S.; Buttner, M. Identification and functional expression of the Arabidopsis thaliana vacuolar glucose transporter 1 and its role in seed germination and flowering. Proc. Natl. Acad. Sci. USA 2007, 104, 2537-2542. [CrossRef] [PubMed]

42. Gottwald, J.R.; Krysan, P.J.; Young, J.C.; Evert, R.F.; Sussman, M.R. Genetic evidence for the in planta role of phloem-specific plasma membrane sucrose transporters. Proc. Natl. Acad. Sci. USA 2000, 97, 13979-13984. [CrossRef] [PubMed]

43. Hackel, A.; Schauer, N.; Carrari, F.; Fernie, A.R.; Grimm, B.; Kuhn, C. Sucrose transporter LeSUT1 and LeSUT2 inhibition affects tomato fruit development in different ways. Plant J. 2006, 45, 180-192. [CrossRef] [PubMed]

44. Fudali, S.L.; Wang, C.; Williamson, V.M. Ethylene signaling pathway modulates attractiveness of host roots to the root-knot nematode Meloidogyne hapla. Mol. Plant Microbe Interact. 2013, 26, 75-86. [CrossRef] [PubMed]

45. Reinders, A.; Sivitz, A.B.; Ward, J.M. Evolution of plant sucrose uptake transporters. Front. Plant Sci. 2012, 3, 22. [CrossRef] [PubMed]

46. Wei, X.; Liu, F.; Chen, C.; Ma, F.; Li, M. The Malus domestica sugar transporter gene family: Identifications based on genome and expression profiling related to the accumulation of fruit sugars. Front. Plant Sci. 2014, 5, 569. [CrossRef] [PubMed]

47. Murugeswari, P.; Azhagumurugan, C.; Rajan, M.K. Nematicidal effect of methanolic root extract of aerva lanata against the root knot nematode, Meloidogyne incognita on bengal gram, Cicer arietinum. World J. Agric. Sci. 2016, 12, 78-83. [CrossRef]

48. André, A.; Maucourt, M.; Moing, A.; Rolin, D.; Renaudin, J. Sugar import and phytopathogenicity of Spiroplasma citri: Glucose and fructose play distinct roles. Mol. Plant Microbe Interact. 2005, 18, $33-42$. [CrossRef] [PubMed]

49. Jones, M.G.; Payne, H.L. Early stages of nematode-induced giant-cell formation in roots of impatiens balsamina. J. Nematol. 1978, 10, 70-84. [PubMed]

50. Sauer, N. Molecular physiology of higher plant sucrose transporters. FEBS Lett. 2007, 581, $2309-2317$. [CrossRef] [PubMed]

51. Hofmann, J.; Wieczorek, K.; Blochl, A.; Grundler, F.M. Sucrose supply to nematode-induced syncytia depends on the apoplasmic and symplasmic pathways. J. Exp. Bot. 2007, 58, 1591-1601. [CrossRef] [PubMed]

52. Martinuz, A.; Zewdu, G.; Ludwig, N.; Grundler, F.; Sikora, R.A.; Schouten, A. The application of Arabidopsis thaliana in studying tripartite interactions among plants, beneficial fungal endophytes and biotrophic plant-parasitic nematodes. Planta 2015, 241, 1015-1025. [CrossRef] [PubMed]

53. Meng, Y.; Chu, Z.H.; Li, X.H.; Xu, C.G.; Wang, S.P. Pathogen-induced expressional loss of function is the key factor in race-specific bacterial resistance conferred by a recessive R gene xa13 in rice. Plant Cell Physiol. 2009, 50, 947. [CrossRef]

54. Hammes, U.Z.; Schachtman, D.P.; Berg, R.H.; Nielsen, E.; Koch, W.; McIntyre, L.M.; Taylor, C.G. Nematode-induced changes of transporter gene expression in Arabidopsis roots. Mol. Plant Microbe Interact. 2005, 18, 1247-1257. [CrossRef] [PubMed] 
55. Hussey, R.S.; Barker, K.R. A comparison of methods of collecting inocula of Meloidogyne species, including a new technique. Plant Dis. Rep. 1973, 57, 1025-1028. [CrossRef]

56. Viglierchio, D.R.; Schmitt, R.V. On the methodology of nematode extraction from field samples: Baermann funnel modifications. J. Nematol. 1983, 15, 438-444. [PubMed]

57. Gong, X.; Liu, M.; Zhang, L.; Ruan, Y.; Ding, R.; Ji, Y.; Zhang, N.; Zhang, S.; Famer, J.; Wang, C. Arabidopsis AtSUC2 and AtSUC4, encoding sucrose transporters, are required for abiotic stress tolerance in an ABA-dependent pathway. Physiol. Plant. 2015, 153, 119-136. [CrossRef] [PubMed]

58. Hu, Y.; You, J.; Li, C.; Williamson, V.M.; Wang, C. Ethylene response pathway modulates attractiveness of plant roots to soybean cyst nematode Heterodera glycines. Sci. Rep. 2017, 7, 41282. [CrossRef] [PubMed]

59. Teixeira, M.A.; Wei, L.; Kaloshian, I. Root-knot nematodes induce pattern-triggered immunity in Arabidopsis thaliana roots. New Phytol. 2016, 211, 276-287. [CrossRef] [PubMed]

60. Bethke, P.C.; Busse, J.C. Validation of a simple, colorimetric, microplate assay using amplex red for the determination of glucose and sucrose in potato tubers and other vegetables. Am. J. Potato Res. 2008, 85, 414. [CrossRef]

61. Schmittgen, T.D.; Livak, K.J. Analyzing real-time PCR data by the comparative C(T) method. Nat. Protoc. 2008, 3, 1101-1108. [CrossRef] [PubMed]

(C) 2018 by the authors. Licensee MDPI, Basel, Switzerland. This article is an open access article distributed under the terms and conditions of the Creative Commons Attribution (CC BY) license (http://creativecommons.org/licenses/by/4.0/). 